\title{
INTERPRETAÇÃO TEÓRICO-POLÍTICA DA GESTÃO DEMOCRÁTICA UNIVERSITÁRIA NO CONTEXTO DAS POLÍTICAS NEOLIBERAIS
}

\author{
INTERPRETACIÓN TEÓRICO-POLÍTICA DE LA GESTIÓN DEMOCRÁTICA \\ UNIVERSITARIA EN EL CONTEXTO DE LAS POLÍTICAS NEOLIBERALES
}

\author{
THEORETICAL-POLITICAL INTERPRETATION OF UNIVERSITY \\ DEMOCRATIC MANAGEMENT IN THE CONTEXT OF NEOLIBERAL \\ POLICIES
}

\author{
Tânia Barbosa MARTINS ${ }^{1}$ \\ Vagno Emygdio Machado DIAS ${ }^{2}$ \\ Sueli Soares dos Santos BATISTA ${ }^{3}$
}

RESUMO: O artigo analisa a gestão democrática universitária a partir de uma reflexão teórico-política das contradições do Estado capitalista como instância de dominação e poder burguês no contexto das políticas neoliberais. O referencial teórico é a concepção de Florestan Fernandes de democracia e autocracia-burguesa em países de capitalismo dependente e subdesenvolvido. Os procedimentos são um estudo teórico que faz referências aos conceitos de democracia, gestão da educação, autonomia universitária e as políticas neoliberais. A limitação do princípio constitucional de autonomiauniversitária produziu uma restrição da gestão democrática pelo modelo de gestãogerencial e pelo projeto neoliberal.

PALAVRAS-CHAVE: Gestão democrática. Autonomia universitária. Neoliberalismo.

RESUMEN: El artículo analiza la gestión democrática universitaria desde una reflexión teórico-política de las contradicciones del Estado capitalista como instancia de dominación $y$ poder burgués en el contexto de las políticas neoliberales. El referencial teórico es la concepción de Florestan Fernandes de la democracia y la autocracia burguesa en países con capitalismo dependiente y subdesarrollado. Los procedimientos son un estudio teórico que tiene como referencia los conceptos de democracia, gestión educativa, autonomía universitaria y políticas neoliberales. La limitación del principio constitucional de autonomía universitaria produjo una restricción a la gestión democrática por el modelo de gestión gerencial y por el proyecto neoliberal.

PALABRAS CLAVE: Gestión democrática. Autonomía universitaria. Neoliberalismo.

\footnotetext{
${ }^{1}$ Universidade Federal de São Carlos (UFSCAR), São Carlos - SP - Brasil. Doutora pelo Programa de PósGraduação em Educação da UFSCar. ORCID: https://orcid.org/0000-0003-4095-4995. E-mail: taniabmartins@yahoo.com.br

${ }^{2}$ Instituto Federal de Educação, Ciência e Tecnologia do Sul de Minas Gerais (IFSULDEMINAS), Poços de Caldas - MG - Brasil. Professor no Programa de Pós-Graduação em Educação Profissional e Tecnológica (ProfEPT). ORCID: https://orcid.org/0000-0001-9102-4283. E-mail: dias.vagno@gmail.com

${ }^{3}$ Centro Estadual de Educação Tecnológica Paula Souza (CEETEPS), São Paulo - SP - Brasil. Professora no Mestrado Profissional do Centro Estadual de Educação Tecnológica Paula Souza (CEETEPS). ORCID: https://orcid.org/0000-0001-8126-9615. E-mail: suelissbatista@uol.com.br
}

RPGE- Revista on line de Política e Gestão Educacional, Araraquara, v. 25, n. esp. 4, p. 1942-1961, dez. 2021. e-ISSN: 1519-9029 DOI: https://doi.org/10.22633/rpge.v25iesp.4.15933 
ABSTRACT: The article analyzes the university democratic management from a theoreticalpolitical reflection on the contradictions of the capitalist State as an instance of domination and bourgeois power in the context of neoliberal policies. The theoretical reference is Florestan Fernandes' conception of democracy and bourgeois-autocracy in countries with dependent and underdeveloped capitalism. The procedures are a theoretical study based on references to the concepts of democracy, education management, university autonomy and neoliberal policies. The limitation of the constitutional principle of university autonomy resulted in a restriction of democratic management by the managerial model and by the neoliberal project.

KEYWORDS: Democratic management. University autonomy. Neoliberalism.

\section{Introdução}

A gestão democrática universitária precisa ser analisada a partir da história das instituições de ensino que são marcadas pelas características históricas e políticas da sociedade brasileira e pelas especificidades do capitalismo periférico (Fernandes, 1976). O contexto brasileiro que se desenvolveu após a década de 80 com o desfecho da ditadura civil-militar e pelo movimento de redemocratização desencadeou a promulgação da Constituição Federal de 1988 e assegurou no artigo 206 a gestão democrática da educação pública como princípio fundamental na educação brasileira. Entretanto, a democracia que se estabelece concretamente está historicamente enraizada numa democracia burguesa, atualmente de cunho neoliberal, apoiada pelo ultraliberalismo, sempre que conveniente.

A crise do Estado estabelecida a partir da década de 1970 é decorrente da queda da taxa de lucro, da saturação do modelo de produção taylorista-fordista no âmbito de reprodução do capital e das greves dos trabalhadores, que resultou na crise do Estado de Bem-Estar-Social diante às demandas do capitalismo (ANTUNES, 2005). Essa crise implicou num processo de reorganização do sistema político e ideológico e de reorganização do processo de reprodução do capital com a disputa entre os projetos neoliberal e socialdemocrata. Conforme Dagnino (2002) instaura-se uma tensão no avanço democrático na medida em que a disputa política entre projetos políticos distintos exige uma sociedade civil ativa e participativa. Nesse cenário, a luta perpassa por disputas de narrativas e significados em torno de interesses e projetos opostos de sociedade, principalmente em torno do papel do Estado no desenvolvimento econômico-social.

A redemocratização política do país resultou na realidade um campo jurídico ambíguo, pois as disputas entre diferentes segmentos e classes sociais culminaram em projetos democráticos utópicos e ficcionais de gestão democrática. A Constituição Federal 
de 1988 reconheceu os direitos de cidadania, mas de modo anômalo não contribuiu de fato com a construção de uma sociedade verdadeiramente democrática na medida em que os direitos são afetados substancialmente pela hegemonia neoliberal, em consonância com a tendência história da constituição de uma democracia burguesia de cunho autocrático ( $\mathrm{F}$ ERNANDES, 1976).

A gestão democrática universitária padece de ingerências decorrentes de determinações históricas e políticas autocráricas e resulta em práticas ambíguas ou meramente formais, cuja tendência é a prática democrática como mediação ou instrumento técnico de solução de conflitos e não a criação de espaços efetivos de participação coletiva.

O presente artigo tem como objetivo refletir sobre os aspectos da gestão democrática universitária a partir de uma reflexão teórico-política, considerando a conjuntura neoliberal como hegemonia política e cultural e destacando as principais evidências que limitam as instituições universitárias de usufruirem dos plenos preceitos democráticos como fundamentos constitucionais.

O artigo está dividido em duas partes, a primeira apresenta uma análise da democracia burguesa em Florestan Fernandes para servir de subsídio teórico para a compreendessão do conceito abstrato de democracia que não considera a realidade do capitalismo de periferia e o papel que o Estado desempenha na dominação e no poder burguês. A segunda analisa a trajetória da gestão universitária no âmbito da democracia neoliberal, iniciada e colocada em prática nas experiências políticas da década de 90 após o processo de redemocratização política e que tem de forma contraditória ampliado os horizontes da autonomia universitária ao mesmo tempo em que tem limitado a própria democracia a partir das reformas na educação.

Enfim, há um processo de recrudescimento do projeto neoliberal pela via de uma "autocracia-burguesa" que pode ser considerada como ultraliberal e promove uma intensificação das políticas neoliberais nas políticas públicas e que escancara a caracterísitica autorcrática sui generis da sociedade brasileira.

\section{A democracia burguesa em Florestan Fernandes}

A interpretação sociológica de Florestan Fernandes (um pensador pouco pesquisado e referenciado na educação) a respeito da burguesia nacional em um país periférico, de "economia capitalista dependente e subdesenvolvida", permitiu a elaboração de um conceito de "democracia-burguesa", indispensável para se refeltir sobre a gestão universitária e a 
conjuntura da reforma neoliberal do Estado e da educaçao no Brasil. Assim, mesmo considerando os distintos momentos históricos entre a análise de Florestan Fernandes e a atual conjuntura e as limitações das interpretações teóricas, é possívem fazer algumas análises sobre a realidade da educação e da democracia.

Conforme Fernandes (1976) o radicalismo democrático, modelo clássico de revolução burguesa, produziu um modelo "democrático-burguês" que se efetivou nos países centrais, mas não se configura como modelo nos países periféricos do capitalismo e nem se desenvolve na mesma direção dos países centrais, ou seja, não há um processo universal de desenvolvimento a que se deve trilhar até alcançar o patamar mais evoluído do capitalismo central. Na periferia do capitalismo há uma dissociação entre desenvolvimento capitalista e democracia e uma associação racional com a autocracia. Conforme Fernandes, o capitalismo associado e dependente ao capitalismo central (imperialista) é um capitalismo "selvagem e difícil" parecido com o modelo do fascismo que evoca o modelo autocrático-burguês,

O que sugere que a Revolução Burguesa na periferia é, por excelência, um fenômeno essencialmente político, de criação, consolidação e preservação de estruturas de poder predominantemente política, submetidas ao controle da burguesia ou por ela controláveis em quaisquer circunstâncias (FERNANDES, 1976, p. 294).

A revolução burguesa como fenômeno essencialmente político implica uma relação predominantemente política com o Estado e com o desenvolvimento capitalista articulado com as políticas de Estado. Daí que o objetivo da burguesia é manter a ordem e salvar o capitalismo periférico, em outros termos, "impedir que a dominação burguesa e o controle burguês sobre o Estado nacional se deteriorem" (FERNANDES, 1976, p. 294).

Fernandes (1976) sempre menciona nos aspectos da revolução burguesa os termos:"atrasada" ou "retardatária" do capitalismo mundial, e por ser uma nação periférica dependente, as ações políticas de classes são profundamente reacionárias, revelando sua essência autocrática, uma "ditadura de classe" ou "ditadura de classe preventiva". Por estar numa condição de dependência e subdesenvolvimento a burguesia não tem muita escolha racional nas alternativas à manutenção de seus interesses e de sua existência na periferia, o que implica em descomprometimento com os fundamentos do idealismo burguês: o liberalismo radical e o nacionalismo democrático-burguês. A burguesia autocrática possui poder econômico, social e político realizado e mantido pelo "controle da maquinaria do Estado", ou seja, uma revolução burguesa reacionária e essencialmente política. 
A burguesia na periferia não precisa e não pode se comprometer com a democracia radical das revoluções burguesas clássicas, e tanto mais se identifica com a autocracia quanto mais faz do Estado o campo de defesa dos seus interesses e privilégios, tornando-a inflexível no emprego da violência institucionalizada. Assim, a dominação burguesa não é só uma força socioeconômica, mas uma força política, uma rede política de defesa e repressão, de poder burguês ligado à empresa do Estado, como fonte de "poder burguês legítimo".

Como o controle do "atraso econômico" efetivamente não implica a supressão da dependência e do subdesenvolvimento, se estabelece a consolidação do modo de dominação burguesa ao nível da política, de modo coercitivo e legítimo e se constitui como uma variante especial da dominação, a variante possível num capitalismo periférico, inclusive se serve do Estado como repressão às tentativas de oposição às concepções burguesas e à sua "ordem legal".

Sobre a força da expressão "violência", Fernandes (1976, p. 303) faz uma observação:

\begin{abstract}
Em suas investigações, o sociólogo não pode deixar de vacilar diante dos resultados de suas observações e de suas interpretações! Parece incrível que semelhante tipo de opressão sistemática possa existir nos dias atuais; e, mais ainda, que ela e os terríveis mecanismos de repressão a que precisa recorrer, possam ser conciliados com os ideais igualitários, de respeito à pessoa humana, aos direitos fundamentais do homem e ao estilo democrático da vida. No entanto, ela aí está - e não apenas na sociedade brasileira (FERNANDES, 1976, p. 303).
\end{abstract}

A modernidade burguesa é conforme Floretsan Fenrnandes definida como máquina de opressão da "classe institucionalizada" que cria "um capitalismo que associa luxo, poder e riqueza, de um lado, à extrema miséria, opróbrio e opressão, de outro" (FERNANDES, 1976, p. 304). A promoção dos interesses comuns da burguesia e das frações burguesas nacionais e internacionais está articulada em torno da defesa da propriedade privada e da iniciativa privada, promovida com o controle do poder político estatal. As divergências entre classes e frações burguesas se resolvem com concessões mútuas e com políticas de ajustamentos, adquirindo um teor conservador e reacionário, por vezes "profundamente reacionário" (FERNANDES, 1976). Como consequência, a forma de ser e de operar da buguesia no capitalismo periférico cria algumas consequências concretas que do ponto de vista do desenvolvimento econômico gera uma situação permanente de subdesenvolvimento, enquanto na vida social uma realidade cotidiana estrutural marcada por desigualdade social, 
míseria e pobreza generalizada, culminando na alienação e marginalização política das camadas populares.

\begin{abstract}
A dupla articulação [desenvolvimento desigual interno e dominação imperialista externo] faz com que vários focos de desenvolvimento economico pré ou subcapitalista mantenham, indefinidamente, estruturas sócio-econômicas e politicas arcaicas ou semi-arcaicas operando como impedimento à reforma agrária, à valorização do trabalho, à proletarização do trabalhador, à expansão do mercado interno etc. Ela também faz com que a especulação se desenrole num contexto que é antes quase colonial que puramente capitalista, em todas as esferas da vida econômica (embora com predomínio do setor industrial e financeiro; e do capitalismo urbano-industrial sobre o capitalismo agrário). Ela impede, também, que as estruturas econômicas efetivamente modernas ou modernizadas fiquem expostas a controle societário eficiente, permitindo que a eclosão industrial continue largamente submetida ao velho modelo dos ciclos econômicos, tão destrutivo para o desenvolvimento orgânico de uma econômia capitalista integrada em escala nacional. A ausência desse controle societário eficiente confere, ainda, uma liberdade quase totalà "grande empresa", nacional ou estrangeira, em todos os ramos de negócios, e à devastadora penetração imperialista em todos os meandros da vida econômica brasileira (FERNANDES, 1976, p. 306).
\end{abstract}

A dominação burguesa converge para o núcleo de poder de decisão, no âmbito do Estado e suas estruturas político-administrativas, a participação militar, que conduz a política da violência legitima durante o processo de manutenção do poder burguês e busca superar a impotência burguesa clássica, a sua fragilidade na forma clássica de democracia burguesa. Assim, a dominação política no Estado é fundamental já que no capitalismo dependente e subdesenvolvido os conflitos sociais não podem ser resolvidos de forma privada na sociedade civil e nem de forma convencional, democrático-burguês, pelo Estado.

A característica fundamental do Estado na periferia é sua natureza autocrática, fundada na natureza autoritária do presidencialismo e na participação militar na condução da dominação burguesa, ou seja, a autocracia burguesa possui uma relação contraditória com o movimento histórico de modelo clássico “democrático-burguês", rompendo com as ideologias e as utopias das repúblicas democráticas burguesas.

Como o rompimento absoluto com o modelo clássico não é possível enquanto racionalidade burguesa acaba produzindo ilusões republicanas e atração das massas. $\mathrm{Na}$ realidade, a burguesia periférica nunca produziu um processo histórico de conquista democrática, pois é sua natureza a situação estrutural autocrática. A burguesia autocrática, no entanto, se apropria do idealismo burguês radical, do nacionalismo, da democracia etc. e caracteriza como uma "demagogia populista" e com uma "modernização dirigida", se 
adaptando a certas causas abstratas como "democracia" e "civilização cristã" sob-rígido ou violento controle do Estado, num processo de dominação burguesa especificamente autoritária e totalitária, caracterizada em momentos históricos de abertura política, como ditadura de classe preventiva.

As utopias radicais da burguesia democrática "poderia confundir-se com a subversão e o comunismo" (FERNANDES, 1976, p. 330) de modo que não faz sentido a discussão social que envereda para o âmbito das massas, ou seja, a questão da democracia na autocracia é um problema de ordem burguesa, mas que na realidade se universaliza e se coloca como um problema de ordem democrática.

\begin{abstract}
Desse ângulo, aquelas pressões punham as classes e os estratos de classe burgueses não diante do problema da democracia (mesmo entendida como uma democracia burguesa); mas, isso sim, diante do problema da ordem (entenda-se: de uma "ordem burguesa" que devia ser salva, posta em bases estáveis e consolidada) (FERNANDES, 1976, 333).
\end{abstract}

A questão principal da democracia é entendida como a manutenção da ordem ou "aparência da ordem" democrática. Assim, a autocracia é um problema de manutenção da dominação burguesa, de uma "democracia forte", no sentido mais hostil como autoafirmação e autoprivilégio, de profunda e persistente impregnação militar e tecnocrata. Segundo Florestan Fernandes não há uma democracia burguesa fraca, mas uma "autocraciaburguesa dissimulada", instalada no Estado como "burguesia burocrática", cujo objetivo é a manutenção da ordem burguesa. Conforme Fernandes (1976, p. 342): "sem a militarização e a tecnocratização intensivas e persistentes, seria impossível colocar o Estado nacional no centro das transformações históricas”.

Os elementos militares e tecnocratas do Estado buscam assumir funções para a garantia da ordem burguesa (ou da democracia burguesa) e para a modernização e a racionalização na articulação política para o domínio da classe burguesa, universalizando o Estado como negócio da nação. A estruturação da burguesa burocrática e as funções do Estado criou um controle político sobre a economia, e não se trata meramente de um Estado político-militar, mas igualmente jurídico-político, em que "autocracia burguesa coloca seu ideal de Estado em conexão histórica com o fascismo e o nazismo" (FERNANDES, 1976, p. $345)$.

Dessa forma, a modernização burguesa do Estado se fundamenta no intervencionismo estatal, pelo controle político do Estado pela da iniciativa privada e pela regulamentação da burguesia e seus estratos, em articulação com a burguesia internacional e 
imperialista, num "capitalismo dirigido pelo Estado".

\begin{abstract}
Aqui, pois, é evidente que o consenso burguês concilia a "tradição brasileira", de democracia restrita - a democracia entre iguais, isto é, entre os poderosos, que dominam e representam a sociedade civil - com a "orientação modernizadora", de Governo forte. A ordem legal epolítica se mantém aberta, democrática e universal, preservando os valores que consagram o Estado de direito; e este Estado se caracteriza, historicamente, por sua vez, na medida em que tudo isso é necessário à monopolização do poder real, da autoridade e do controle das fontes de legitimidade pelas classes burguesas e suas elites" (FERNANDES, 1976, p. 347).
\end{abstract}

A democracia brasileira possui traços caracteríticos da condição histórica do capitalismo periférico e tem produzido uma burguesia de Estado que limita não apenas o desenvolvimento pleno da democracia e da política como tem impedido o próprio desenvolvimento economico-social da sociedade.

\title{
A gestão universitária democrática liberal
}

As universidades definem suas finalidades acadêmicas, científicas, tecnológicas e formativas a partir dos princípios de autonomia universitária e de gestão democrática da educação, apresentadas na Constituição Federal de 1988. Apesar dos avanços democráticos no campo da educação com a Constituição Federal, reconhecida como constituição cidadã, que estabelece o Estado Democrático de Direito, o acesso e a permanência à educação universitária se apresentam como um direito frágil. A universidade está cada vez mais condicionada pelas demandas econômicas e políticas da da iniciativa privada que dificultam na prática a implementação de uma educação público-estatal.

Segundo Bianchetti e Sguissardi (2017), a ideia de universidade no Brasil se origina no período do Brasil Imperial, mas começa a se concretizar após a Revolução de Trinta (1930), marcada por várias fases de desenvolvimento e reestruturação em que se tencionava o modelo de universidade. A estrutura da universidade é regida pela Lei n. 5.540 de 1968 que estabeleceu a natureza estrutural, política e pedagógica do sistema de educação superior e criou alternativas de estrutura institucional com o formato de universidade sob a forma de autarquia, subordinada ao conselho universitário, regido na forma de estatuto e presidida pelo reitor. É a partir da reforma universitária oriunda de uma ditadura civil-militar, de cunho não democrático, que a universidade é definida pela autonomia didática e científica, administrativa, financeira e patrimonial. A autonomia didática é compreendida com a 
liberdade para estabelecer os objetivos e a organização do regime didático e escolar e de criar cursos, programas, currículos sem quaisquer restrições doutrinárias ou políticas; a autonomia administrativa consiste na possibilidade de a universidade, com aprovação do Conselho Federal ou Estadual de Educação, reformar e alterar estatutos, regimentos e indicar reitores para aprovação pelo governo mediante lista-tríplice, e de criar suas instâncias de decisões, dentre outros; e, por fim, a autonomia financeira e patrimonial que versa sobre a administração do patrimônio e a execução das políticas universitárias, especialmente o orçamento e de dispor sobre doações e heranças etc.

A reforma universitária da ditadura civil-militar de 28 de novembro de 1968 representa uma dissimulação democrática, portanto, se estabelece de forma contraditória, pois ao mesmo tempo em que o governo institui a autonomia universitária, instaura a criação de mecanismos de intimidação da autonomia por atos jurídicos e políticos como o Ato Institucional (AI-5), de 13 de dezembro de 1968 e o Decreto Lei n. 477 de 16 de fevereiro de 1969 (FAVERO, 1988). Assim, a universidade se estrutura em uma ordem política e ideológica autoritária e totalitária, alinhada aos governos da ditadura civil-militar e à ideologia desenvolvimentista que serviu de parâmetros para as reformas educacionais alinhadas ao acordo MEC- USAID. Assim, o conjunto de decretos, resoluções e pareceres emitidos por diferentes órgãos públicos do período se destinavam a legitimar uma orientação tecnicista para aumentar a eficiência e a produtividade do aparato estatal e ao mesmo tempo limitar os aspectos inerente à democracia e à cidadania como a extinção das liberdades individuais, políticas e de expressão. Nessa conjuntura, a expansão da participação do setor privado na educação universitária foi amplamente facilitada com base na lógica da racionalidade e da eficiência dos setores produtivos, sob o jugo da ideologia do Capital Humano de Theodore W. Schultz e Gary S. Becker, justificada como medidas universalizantes para atender o território nacional.

A Lei n. 5.540 de 1968 reflete as demandas da formação sistêmica em conformidade com os processos de modernização conservadora mediante medidas autoritárias destinadas a criar as condições de normalização das atividades precípuas às universidades. A intenção é introduzir no planejamento estatal o planejamento do sistema de educação superior, segundo uma lógica modernizadora de caráter privatista- empresarial.

As novas forças no poder, com o golpe de Estado de 1964, não iriam promover uma mudança radical nas tendências modernizantes da educação superior que vinham marcando a política de educação superior durante os governos nacional-reformistas. Como observa Martins (1988, p.13) o que mudava era o sentido histórico a determinar os fins dessa modernização. Liquidado o populismo, perder-se-ia seu vínculo com o 
desenvolvimentismo de um certo capitalismo "autônomo", de "coloração nacionalista". Agora, a educação superior, modernizada, seria um instrumento a mais a contribuir para a consolidação do projeto de desenvolvimento "associado e dependente" dos centros hegemônicos do capitalismo internacional. A "racionalização e a eficiência" defendidas ao final do regime anterior e, então, por diversas consultorias, comissões e grupos de trabalho (Relatórios Atcon, da Eapes/MEC-Usaid e do GT Reforma Universitária), além dos Decretos n. ${ }^{\circ} 53 / 66$ e 252/67, iriam constituir o conceito essencial da Lei $\mathrm{n}^{\circ}{ }^{\mathrm{O}} 5.540 / 68$ e ajudar a prover a segurança donovo modelo de crescimento (SGUISSARDI, 2004, p. 39).

Durante a década de 80 , em decorrência da luta política por participação nos rumos da vida política nacional, constituíram-se vários movimentos e experiências democráticas favorecidas ao próprio processo de redemocratização política do país. No campo educacional, a promulgação da Constituição Federal de 1988 representou um grande avanço ao apresentar como princípio da educação nacional a gestão democrática da educação pública. A constituição representa um avanço sem precedentes e promove uma ruptura com a exclusão das massas na participação política. Nos direitos fundamentais, por exemplo, o artigo 10 estabelece a participação dos trabalhadores e empregados em órgãos colegiados da esfera pública e o artigo 65 assegura que os interesses dos trabalhadores e empregados são objetos de discussões e deliberação nos colegiados dos órgãos públicos. Ou seja, são fundamentos e diretrizes constitucionais que compreendem o Estado Democrático de Direito, entidade público-estatal, que significa a garantia de instrumentos e mediações para atender às necessidades públicas da população com a participação democrática desta mesma população, ou seja, a formação e a instituição da condição de cidadania e de um Estado cidadão.

Assim, o princípio da gestão democrática deve conduzir as orientações legais e institucionais no setor público-estatal. Como efeito, a Lei de Diretrizes e Bases da Educação Nacional (LDB) n. 9.394, de 1996, a efeito e subsidiada pela Constituição Federal de 1988, afirma no artigo I que a gestão da educação deve ocorrer com a participação dos profissionais da educação na elaboração do projeto pedagógico e no artigo II, que a participação da comunidade escolar deve ocorrer em conselhos e equivalentes. Apesar de o novo ordenamento jurídico apresentar, de modo bastante, significativo os significados das lutas pelas liberdades democráticas, tais como a conquista da liberdade de organização partidária, pelo retorno de eleições para governantes que culminou no movimento "Diretas Já", e a necessidade de construção de experiências e de processos de gestão democráticos no setor público-estatal, o princípio é atrofiado pela conjuntura da ideologia neoliberal no país, que se inicia como cultura dominante a partir da década de 90. Conforme Cury: 
A Constituição da República de 1988 foi promulgada no momento em que os intensos ventos vindos da Inglaterra, dos Estados Unidos, da Austrália e do Chile sopravam em sentido inverso aos direitos sociais tão claramente proclamados. A postulação de um recuo do papel do Estado nestes direitos e na economia acabou por confirmar a não efetivação de muitas das expectativas (CURY, 2013, p. 205).

A Constituição Federal de 1988 que abriu as portas para a inserção dos princípios da democracia e da cidadania como fundamentos de uma sociedade moderna, no intuito de superar as formas ditatoriais de organização da sociedade, também abriu as portas para a inserção e a manutenção de uma perspectiva democrática burguesa neoliberal no âmbito do Estado e da sociedade, criando desde a década de 80 uma orientação ou cultura propícia à consolidação do neoliberalismo a partir da década de 90, em projetos e programas de reformas neoliberais.

Apesar do avanço constitucional em termos de conquistas no campo da democracia e da cidadania, a gestão democrática impactou as universidades que desenvolveu uma cultura democrática com a participação dos servidores públicos e o direito de conceber, planejar, deliberar, acompanhar e avaliar as ações. No entanto, a garantia constitucional da gestão democrática no setor público não se efetiva plenamente na medida em que a democracia nas universidades é limitada com a negação do pleno exercício da autonomia, quando não é permitido, por exemplo, a discussão sobre a finalidade social da educação que é preestabelecida por um ideário neoliberal e o alinhamento imediato da educação ao mercado. Essas ambiguidades se estendem para o plano das políticas públicas que procuram retirar ou dificultar a própria gestão democrática no setor público, na medida em que se considera a gestão gerencial do ideário neoliberal como fator objetivo.

As experiências neoliberais das décadas de 80 e 90 foram produzidas no contexto de experiências democráticas ou de processos de abertura democráticas em países ditatoriais ou autoritários como na América latina a exemplo do Chile, que serviu de laboratório de experiências neoliberais ainda no final da década de 70. Há uma nítida e direta relação entre políticas neoliberais e posturas violentas e autoritárias sejam em regime ditatoriais ou em democracias burguesas. Os processos neoliberais para aperfeiçoar a universidade a partir de princípios democráticos se desenvolveram com as tensões políticas, econômicas e sociais da década de 90 e se apresenta, de um lado, numa perspectiva mais radical, de violência, desde casos mais extremos a moderados, de outro, numa perspectiva pseudodemocrática ou democrática-burguesa, concretamente não democrática, pois envolve limitar e retirar direitos e restringir a participação diante das políticas neoliberais que são inexoravelmente 
impopulares. Conforme Sguissardi (2014, p. 92), o projeto político em âmbito global "é muito bem demarcado por uma economia mundial e pela substituição do Estado do Bem-EstarSocial ou, no caso brasileiro, do Estado Nacional-Desenvolvimentista em crise, pelo chamado neoliberalismo".

As ideias neoliberais surgem nos anos 40 e combatem o intervencionismo estatal e as políticas do Welfare-State. A partir da década de 70 surgem as primeiras experiências com Donald Reagan, nos Estados Unidos, e Margareth Thatcher, na Inglaterra. Não obstante as especificidades de cada país, em linhas gerais, os governos neoliberais limitam o tamanho do estado ao mínimo, evitam regulamentações desnecessárias, promovem privatizatizações de empresas estatais, abrem a economia nacional e estimulam a livre competitividade no mercado. Ademais, as políticas neoliberais favorecem a economia mundial em sua face de predominância financeira, pois impõem um ambiente que permitem o desenvolvimento do capital em sua volatilidade (PAULANI, 2008). Mas, ao mesmo tempo, é um neoliberalismo que necessita de um Estado forte em termos de investimento e políticas públicas para a iniciativa privada e para a manutenção das condições capitalistas, continuando os preceitos de um capitalismo de Estado ou capitalismo burguês.

Dardot e Laval (2016) analisam o neoliberalismo como uma racionalidade política mundial e que impõem à sociedade e ao Estado a lógica do capital e cria uma nova subjetividade nas pessoas. Acrescenta que o consenso neoliberal ampliou radicalmente e diluiu as reflexões críticas ao neoliberalismo que por sua vez se alimenta da narrativa ideológica das próprias crises econômicas e sociais que produz. Assim, o neoliberalismo propõe não apenas a reforma do Estado, mas a colonização dos sujeitos com uma subjetividade que se baseia numa racionalidade caótica. Conforme destaca Paulani (2008), o neoliberalismo se desenvolve num contexto de crise permanente, de centralização de capitais, de fusões, aquisições e desregulamentações e de concentração na produção de setores monopolistas e de capital aberto. O projeto neoliberal se assume como o único caminho para resolver o problema da crise econômica dos anos 80 .

Durante o governo de Fernando Henrique Cardoso (1994-2002) concretizou-se um ousado plano de reforma do Estado subsidiada pelo Plano Diretor da Reforma do Aparelho do Estado de 1995, elaborado pelo Ministério da Administração Federal e da Reforma do Estado (MARE), comandado por Luiz Carlos Bresser Pereira, a partir da doutrina neoliberal e do modelo de administração pública gerencial. 
A reforma do Estado envolve quatro problemas que, embora interdependentes, podem ser distinguidos: (a) um problema econômicopolítico - a delimitação do tamanho do Estado; (b) um outro também econômico-político, mas que merece tratamento especial - a redefinição do papel regulador do Estado; (c) um econômico-administrativo - a recuperação da governança ou capacidade financeira e administrativa de implementar as decisõespolíticas tomadas pelo governo; e (d) um político - o aumento da governabilidade ou capacidade política do governo de intermediar interesses, garantir legitimidade, e governar. Na delimitação do tamanho do Estado estão envolvidas as ideias de privatização, publicização e terceirização. A questão da desregulação diz respeitoao maior ou menor grau de intervenção do Estado no funcionamento do mercado. No aumento da governança temos um aspecto financeiro: a superação da crise fiscal; um estratégico: a redefinição das formas de intervenção no plano econômico-social; e um administrativo: a superação da forma burocrática de administrar o Estado. No aumento da governabilidade estão incluídos dois aspectos: a legitimidade do governo perante a sociedade, e a adequação das instituições políticas para a intermediação dos interesses. (BRESSER-PEREIRA, 1997, p.8)

Bresser-Pereira (1997) enfatiza que o objetivo da reforma do Estado é a reconstrução do Estado, isso significa que não se trata apenas da superação da gestão burocrática pela gestão gerencial, mas também pela refundação das estruturas institucionais do Estado, adequadas e ajustadas aos interesses privados da sociedade civil, o que ao contrário do que se imagina não deixa de ser um retorno ao Estado patrimonialista, o que ainda não deixa de ser ou representar uma forma específica de intervenção do Estado na economia. Bresser-Pereira, em alguns textos, procura sempre afirmar que a reforma gerencial proposta como substituição à gestão burocrática, não é uma política neoliberal em termos radicais, no sentido de completa ausência ou intervenção na economia, o que pressupõe e confirma que o Estado (forte) continua tendo um papel central na consolidação do capitalismo. Essa forma de apresentar o problema tem o objetivo afirmar a independência, autonomia e objetividade do gerencialismo enquanto administração racional, garantindo-se eficiência na gestão pública, mas no fundo é uma tentativa de dissimular a postura autoritária e violenta do neoliberalismo ao se impor sobre o Estado e redefinir (reformar) suas instituições e as políticas públicas.

O modelo gerencial se inspira na administração de empresas, apesar de alegações que a tratam como uma ciência objetiva e se tornou propriamente um modelo científico da administração pública, com ênfase na produtividade, nos resultados e na interação dos agentes privados e/ou organizações da sociedade civil com o setor público. O Estado se desloca do papel de provedor direto dos serviços sociais e promove contratos de gestão com representantes da sociedade civil. Conforme Araújo e Castro (2011) a reforma gerencial do Estado é criada num cenário de "difusão da ideia de que o setor privado é mais eficiente do 
que o público, portanto, as suas diretrizes organizacionais devem ser aplicadas no setor público numa forma de racionalizar os serviços e reduzir o gasto público" (ARAÚJO e CASTRO, 2011).

A concepção de educação num Estado gerencial é definida (como se já não o fosse), como atividade competitiva e não exclusiva do Estado, mas cuja consequência é modificar o modelo atual de universidade que na nova concepção passaria a ser administrada por fundações públicas de direito privado, mediante contratos de gestão e proposição do fim da gratuidade do ensino. Ademais, tal modelo "liberaria o Estado do dever constitucional de manutenção integral das instituições e as responsabilizaria pela busca permanente dos recursos para sua própria manutenção, junto a órgãos financiadores oficiais ou do mercado" (SGUISSARDI, 2014, p. 92).

O conjunto dos elementos que contribuem com a redefinição da finalidade social da universidade no projeto neoliberal é afetado pela lógica privatista-empresarial. A autonomia universitária é cerceada na medida em que se tende a ajustar às finalidades externas, de interesse privado, instauradas e articuladas por políticas públicas, alinhadas estritamente ao mercado. Como consequência de direcionar diretamente a universidade cada vez mais para satisfazer as demandas do mercado, gera-se prejuízos aos princípios constitucionais da universidade, especialmente a democracia universitária. Assim, em linhas gerais, os governos após o processo de redemocratização política, especialmente o governo de FHC, sob a égide da conjuntura e da ideologia neoliberal e das políticas de reforma do Estado brasileiro, deu início de modo destacado, a ataques estruturais à autonomia e à gestão da educação universitária.

Há uma série de políticas voltadas à abertura indiscriminada de cursos e instituições privadas, sem a devida preocupação e mensuração da qualidade, isto é, sem mecanismo de regulação, gestão e avaliação dos aspectos formativos e qualitativos da formação, dos cursos e das instituições e sem preocupação com o corpo docente, sua carreira e valorização profissional. As políticas de aligeiramento da formação, ao modo da massificação do ensino, se ampliam com o fortalecimento da educação a distância $(\mathrm{EaD})$ e a criação de instituições de ensino (licenciatura) que excluem a tríade ensino-pesquisa-extensão. Tais políticas culminaram com a Portaria n. 2.117, de 06 de dezembro de 2019, que autoriza as instituições a oferecer $40 \%$ da carga horária de cursos à distância. Na mesma direção há um processo de incentivo ao ensino profissionalizante ou de caráter profissional, isto é, diretamente envolvido com as demandas, necessidades ou ideologias mercantis, numa perspectiva economicista de educação no ensino superior, desde os cursos tecnológicos ou superiores de tecnologia. Assim 
também se delineia a perspectiva de formação de professores baseado na perspectiva individualizante, subjetivista e profissionalizante, de acordo com a famigerada pedagogia das competências. Assim, os próprios conselhos nacionais de educação estão sem a devida participação de especialistas ou comunidade escolar estabelecendo políticas de cunho privado-empresarial na educação-pública (Resolução CNE/CP 2/2019, Resolução CNE/CP $1 / 2020)$

Ao contrário do que estabelece o princípio constitucional e da lei maior da educação, a autonomia tende a se restringir a mera formalidade ou a uma mudança conceitual, como captação externa de recurso, estabelecendo uma visão de diferenciação institucional e de diversificação das fontes de financiamento, inclusive, em conformidade, com as próprias teses dos organismos multilaterais, ao exemplo do Estado mínimo, uma educação mínima. Essas mudanças buscam reduzir a política e a gestão da educação a procedimentos, processos e execução de políticas governamentais que salientam a aproximação do governo aos grupos econômicos e empresariais, mediados por políticas educacionais, em que a educação passa a ser entendida como diretamente articulada aos interesses econômicos e ao mercado de trabalho.

Portanto, a Constituição Federal e a própria LDB, são fundamentada numa conjuntura história democrática, pós-ditadura civil-militar, mas numa concepção burguesa de democracia, apropriada pela ideologia neoliberal, que assegura a reforma minimalista do Estado. Assim, apresentam consonância formal com os valores democráticos: escola pública, autonomia, participação, pluralidade, gestão democrática, dentre outros, mas reféns de efetivas políticas públicas neoliberais que conduz ao esvaziamento de tais conceitos e práticas.

Cabe salientar que com uma perspectiva gerencialista de gestão da educação, que é a base supostamente objetiva da política ideológica do neoliberalismo, são promulgados processos que limitam os aspectos progressistas da Constituição Federal e da LDB, e que os deturpam, por exemplo, com a diversificação das fontes de investimentos, com a inauguração de um sistema nacional métrico de avaliação, de formas de avaliação padronizadas da educação com base em metas e procedimentos baseados no mérito, nas competências, produtividade, inclusive, servindo de avaliação de desempenho escolar e docente.

A partir de 2003, durante os governos petistas, se destacou, a despeito das expectativas e de inegáveis avanços no campo da educação, certa continuidade nos liames gerais da racionalidade nas políticas neoliberais, que também produziram a limitação da autonomia universitária e a continuidade das reformas gerenciais da educação. Assim, permaneceu a 
lógica do mercado no campo da educação e a concepção e gestão gerencial e público-privada na universidade, dando certa manutenção e continuidade ao projeto neoliberal do governo anterior pertencente ao Partido da Social-Democracia Brasileiro (PSDB).

O que mais transparece nesse período "progressista" é a concepção economicista que compreende a questão do financiamento universitário como articulado à diversificação de fontes de investimento, isto é, à busca de alternativas de financiamento, portanto, o atendimento às políticas de parcerias público-privadas, e outras formas para se promover recursos privados ou empresariais ou mesmo de fundos de pensão para fomentar a universidade. As novas estratégias de captação de recursos acentuam uma visão privatista da autonomia universitária, acompanhando as diretrizes da reforma gerencial do Estado.

Assim, a visão de gestão da educação também fica restrita a parâmetros fundadas em metas, indicadores e produtividade, as finalidades são agora os resultados e não mais a educação, degenerando ou ressignificando conceitos como participação e democracia e, por consequência, a função social pública da universidade. A autonomia como princípio pétreo constitucional é quebrado com a astúcia de sua limitação por ressignificação e, da mesma maneira, a gestão da educação não é mais entendida de forma ampla, mas como recurso ou processo de gestão.

Apesar do reconhecimento dos princípios democráticos na Constituição Federal e na LDB sustentado numa perspectiva progressista de cidadania e democracia, as políticas públicas para a educação se comportam como suportes à lógica própria dos diversos projetos políticos da conjuntura, tornando as propostas e projetos educacionais autoritários não apenas com relação ao conteúdo neoliberal do projeto que desregulamenta direitos historicamente conquistados, mas como deliberação de cúpula sem o devido respaldo participativo ou no âmbito legislativo e executivo, sem a participação das escolas, das Universidades e Institutos Federais, das entidades e associações da educação enfim, da comunidade.

O governo Bolsonaro (2019-2022) foi eleito pelo Partido da Social Liberal - PSL após uma campanha marcada pela ausência de debates entre os candidatos e pelo uso massivo e manipulatório das redes sociais. Em sua ideologia partidária o PSL estabelece como ideias o combate à corrupção, aos desequilíbrios morais e sociais e as políticas que visem "conscientizar" a respeito dos males provocados pelo comunismo e socialismo, dentre outros. Especialmente, entre seus ideais destacam-se a proteção à propriedade privada e a redução do tamanho do Estado, assim como o incentivo a todas as formas de livre iniciativa privada, mediante a adoção de políticas econômicas liberais.

Nos primeiros anos de governo, como exemplo de políticas autocráticas mais 
diretamente relacionadas ao campo da educação, dentre várias outras, apresentou o Programa Institutos e Universidades Empreendedoras e Inovadoras (Future-se), denominado Projeto Future-se, que possuiu quatro versões, a última enviada ao Congresso como PL 3076/2020, estabelece a concepção de educação e de universidade. O Future-se é a idealização de um projeto de educação superior que visa articular estrategicamente a educação e o mercado, conforme Baima (2019) transformando a personalidade jurídica das instituições federais de ensino superior, que se transforma em instituições públicas de direito privado. Configura-se como o ataque mais profundo ao carater público-estatal das universidades e representa diretamente a perspectiva autocrática em educação.

As análises realizadas por intelectuais e representantes de associações, tais como a Associação Nacional de Pós-Graduação e Pesquisa em Educação (ANPED), a Associação Nacional dos Dirigentes das Instituições Federais de Ensino Superior (ANDIFES), o Conselho Nacional das Instituições da Rede Federal de Educação Profissional, Científica e Tecnológica (CONIF), dentre outros, sobre o conteúdo do programa e o modo como foi apresentado representa um dos maiores ataques à universidade pública. O programa Future-se foi apresentado de forma abrupta e consolidado sem a participação das universidades nem mesmo para colaborar com a elaboração da proposta. Destaca-se o apressamento, a falta de discussão, de participação e a forma autoritária da apresentação e de imposição de um programa de interesse público, com argumento ideológico e infundado de crise no sistema de financiamento público da universidade.

O programa não somente feriu o princípio da autonomia universitária previsto na Constituição Federal, como foi proposto com o objetivo de destruir o modelo atual de universidade pública, incluindo os Institutos Federais e os Centros Federais de Educação Tecnológica. Nas palavras de Baima (2019), o Projeto Future-se possibilitaria a alienação do patrimônio destas instituições, a contratação de docentes e de pessoal técnico sem a necessidade de concurso público, o incentivo aos projetos privados e ao empreendedorismo, além da implementação de mecanismos de premiação bastante comprometida com valores diversos ao estritamente acadêmico. $\mathrm{O}$ autor destaca a dependência da produção intelectual à possibilidade de comercialização, uma vez que passaria a ser condicionada à resultados do mercado. E acrescenta que o fim maior do Future-se é extinguir a autonomia administrativa das instituições federais, por meio da introdução de gestores executivos externos à universidade.

O programa Future-se pressupõe a gestão universitária gerida por Fundos Patrimoniais, vinculados às vicissitudes próprias dos voláteis mercados financeiros, 
representando uma lógica das reformas neoliberais em desenvolvimento no país, que convertem os sistemas educacionais em nichos de mercado, numa associação direita entre educação e mercado, ao passo que tende a destituir a educação como entidade público-estatal.

Essa orientação política neoliberal procura dar continuidade a implementação do "Estado Gerencial” concebido como uma "democracia moderna", em que as privatizações não deveriam ser concebidas com pessimismo, mas como um indicativo da necessidade de consolidar o Estado gerencial. Nesse contexto, não há interesse no fortalecimento das universidades e institutos federais, pelo contrário, o governo federal se esforça para sucatear, precarizar e desqualificar a partir de uma postura ideológica anticientífica e, oportunamente, operacionalizar a nova racionalidade, assegurando uma gestão de cunho gerencial e com universidades geradoras de lucros, em moldes estritamente privatista-empresarial.

Articulados com o Programa Future-se, um projeto de reforma da educação universitária, há em curso uma série de projetos e políticas de reforma neoliberal do Estado, articuladas e fundamentadas com a reforma gerencial das instituições públicas- estatais. A reforma administrativa (PEC 32/2020) representa, por exemplo, a adoção de medidas drásticas por um viés político-ideológico de cunho neoliberal, fundado em uma gestão gerencial e na redefinição do papel do Estado, seria a conclusão da reforma do Estado iniciada na década de 1990, agora feita com a devida ausência de consulta e participação popular, passando por cima de preceitos constitucionais.

\section{Considerações Finais}

Nesse artigo mostrou-se que a gestão democrática universitária não pode ser explicada por si mesma e nem apenas como princípio, sem que se compreenda a natureza do próprio Estado e dos processos histórico-políticos. É somente pela consideração dos processos sociais em que se dá a reprodução do capital e a configuração do Estado, que se podem tecer considerações sobre a gestão democrática universitária. Tendo isso em vista, a compreensão sustentou-se, especialmente, em Florestan Fernandes, com base na sua concepção de democracia e autocracia-burguesa em países de capitalismo dependente e subdesenvolvido e nas contribuições de estudiosos do campo da educação universitária. Conclui-se que as razões pelas quais as instituições não absorvem plenamente os princípios da gestão democrática associam-se à ideologia do neoliberalismo associada a políticas autoritárias, com objetivo de articular educação pública e dominação burguesa. 


\section{Referências}

ANTUNES, R. Os sentidos do trabalho. São Paulo: Boitempo, 2005.

ARAÚJO, S.; CASTRO, A. M. D. Gestão educativa gerencial: superação do modelo burocrático? Ensaios: aval. Pol.públ. Edu., Rio de Janeiro, v. 19, n. 70, p. 81-106, jan./mar. 2011.

BAIMA, E. Future-se: destruição do ensino superior. O Trabalho, 2019. Disponível em: https://otrabalho.org.br/future-se-destruicao-do-ensino-superior/. Acesso em: 10 out. 2020.

BIANCHETTI, L.; SGUISSARDI, V. Da universidade à commoditycidade: ou de como e quando, se a educação/formação é sacrificada no altar do mercado, o futuro da universidade se situaria em algum lugar do passado. Campinas, SP: Mercado de Letras, 2017.

BRESSER-PEREIRA, L. C. B. A Reforma do estado dos anos 90: lógica e mecanismos de controle / Luiz Carlos Bresser Pereira. Brasília, DF: Ministério da Administração Federal e Reforma do Estado, 1997. 58 p. (Cadernos MARE da reforma do estado; v. 1)

CURY, C. R. J. Os sentidos da Constituição. Revista Brasileira de Política e Administração da Educação, v. 29, p. 195-206, 2013.

DAGNINO, E. (org.). Sociedade civil e espaços públicos no Brasil. São Paulo: Paz e Terra/Unicamp, 2002. 364 p.

DARDOT, P.; LAVAL, C. A nova razão do mundo: ensaio sobre a sociedade neoliberal. São Paulo: Editora Boitempo, 2016. 402 p.

FÁVERO, M. L. A. Autonomia universitária: necessidade e desafios. Cadernos CEDES, n. 22, 1988, p. 7-16.

FERNANDES, F. A revolução burguesa no Brasil: ensaios de interpretação sociológica. 2. ed. Rio de Janeiro: Zahar, 1976.

PAULANI, L. Brasil Delivery: servidão financeira e estado de emergência econômica. São Paulo: Boitempo, 2008.

SGUISSARDI, V. A universidade neoprofissional, heterônoma e competitiva. In:

MANCEBO, D.; FÁVERO, M. L. A. Universidade. Políticas, avaliação e trabalho docente. São Paulo: Cortez, 2004.

SGUISSARDI, V. Estudo Diagnóstico da Política de Expansão da (e acesso à)educação superior no Brasil - 2002-2012. 2014. 


\section{Como referenciar este artigo}

MARTINS, T. B.; DIAS, V. E. M.; BATISTA, S. S. S. Interpretação teórico-política da gestão democrática universitária no contexto das políticas neoliberais. Revista on line de Política e Gestão Educacional, Araraquara, v. 25, n. esp. 4, p. 1942-1961, dez. 2021. eISSN:1519-9029. DOI: https://doi.org/10.22633/rpge.v25iesp.4.15933

Submetido em: 20/08/2021

Revisões requeridas em: 12/10/2021

Aprovado em: $15 / 11 / 2021$

Publicado em: 08/12/2021 